\section{Neurosis induced by home monitoring of blood glucose concentrations}

\author{
S F Beer, C Lawson, P J Watkins
}

Diabetic Department, King's College Hospital, London SE5 9RS

S F Beer, MRCP, registrar

C Lawson, RGN, liaison sister

P J Watkins, FRCP, consultant

Correspondence to:

Dr Watkins.

Br Med f 1989;298:362 describe three such patients.

\section{Case reports}

The introduction of home monitoring of blood glucose concentrations in the 1970 s was a major advance. ${ }^{1}$ A number of patients, however, become obsessed with the results and develop a disruptive neurosis. We

Case 1-A 53 year old woman was referred with recurrent severe hypoglycaemia. Insulin dependent diabetes mellitus had been diagnosed 43 years previously. Treatment had been by once daily soluble insulin and protamine zinc insulin for many years, with control assessed by regular urine testing. Six months before examination her treatment had been changed to soluble insulin and insulin zinc suspension (Ultratard; Novo) and she had been taught to monitor blood glucose concentrations with a meter. Her diet had not changed. She had soon overreacted to her readings of glucose concentrations and had changed her insulin regimen daily. Attacks of hypoglycaemia resulted in three or four hospital visits a week, and her husband was giving her glucagon daily. On examination she showed no complications, and haemoglobin $A_{1}$ concentration was $11 \cdot 2 \%$ (normal range $4 \cdot 0-8 \cdot 0 \%$ ). After re-education she took a constant dose of insulin and had hypoglycaemia less often. Concentration of $\mathrm{HbA}_{1}$ at follow up was $11 \cdot 1 \%$.

Case 2-A 56 year old woman referred with recurrent severe hypoglycaemia had been treated with once daily protamine zinc insulin for 22 years apart from a brief period of twice daily treatment six years before referral. One year before referral she had been instructed in home monitoring of blood glucose concentrations and converted to a twice daily regimen of neutral insulin injection (Actrapid; Novo) and insulin zinc suspension (Monotard; Novo). Shortly afterwards she had begun to make large changes in her insulin dose daily, which had led to as many as 30 episodes of hypoglycaemia in 44 days, many leading to unconsciousness. She had not altered her diet in any way. On examination she had a few microaneurysms and no other evidence of diabetic complications. Concentration of $\mathrm{HbA}_{1}$ was $11 \cdot 1 \%$. After re-education she had only one episode of hypoglycaemia in two months. Only one change was made in her insulin dose, and on repeat testing $\mathrm{HbA}_{1}$ concentration was $10 \cdot 2 \%$.

Case 3-A 20 year old woman was referred with multiple disruptive episodes of hypoglycaemia. She had been receiving twice daily insulin for 10 years. Four years previously, at the time of conversion to U100 insulin, she had been instructed in home monitoring of blood glucose concentrations and soon became frantic at the fluctuations in her results. She made daily changes in her insulin dose (often up to $100 \%$ ), resulting in disruptive hypoglycaemia. She had tried virtually every possible insulin regimen; when seen she was using a NovoPen injection device. Clinical examination showed no diabetic complications, and $\mathrm{HbA}_{1}$ concentration was $8 \cdot 6 \%$. After re-education she maintained a regular insulin dose and had substantially fewer episodes of hypoglycaemia. On repeat testing $\mathrm{HbA}_{1}$ concentration was $8 \cdot 4 \%$.

\section{Comment}

These patients had no serious problems with diabetes until they started monitoring their blood glucose concentrations, when they failed to understand what fluctuations to expect. All changed their insulin doses daily, and disabling hypoglycaemia resulted. All made several glucose readings every day and obsessively kept records. All feared complications and tried to achieve "normal" blood glucose concentrations. In addition, all of them had been labelled as having "brittle" diabetes $^{2}$ and referred for better control. For reeducation they were shown how to detect peaks and troughs in glucose concentrations and were instructed to modify their insulin dose no more than once or twice weekly.

Home monitoring of blood glucose concentrations, though benefiting most patients, may lead to neurosis in patients with an obsessional trait. The problem often arises when patients are asked to achieve normal blood glucose concentrations to avoid complications but inadequately comprehend the expected blood glucose profile.

\footnotetext{
1 Sonksen PH, Judd SL, Lowy C. Home monitoring of blood glucose. Lancel $1978 ; i: 729-32$.

2 Pickup J. Britle diabetes. Oxford: Blackwell Scientific, 1985.

(Accepted 21 October 1988)
}

\section{Which type of hospital discharge report reaches general practitioners most quickly?}

\author{
A R Kendrick, D J Hindmarsh
}

Weybridge Health Centre, Weybridge, Surrey KT13 8DU

A R Kendrick, MRCGP, general practitioner

D J Hindmarsh, DCH, general practitioner

Correspondence to: $\mathrm{Dr}$ Kendrick.

BrMed F 1989;298:362-3
Patients recently discharged from hospital often have to be followed up by their general practitioners in the absence of any information from the hospital because of delays of several days before a discharge note reaches the practice. ${ }^{1-3}$ Some hospitals have combined the form for prescribing treatment for patients to take home with them with the discharge note. Thus a note is automatically written to the general practitioner for any patient who is given drugs to take home before that patient can be discharged. The note should be posted before, or at the time of, discharge.
This combined discharge note and prescription form should reach the general practitioner more quickly on average than a separate discharge note, which is usually written when the junior hospital doctor can find time, not necessarily at the time of the patient's discharge. We carried out a study to assess this.

\section{Methods and results}

Between 1 May 1987 and 30 April 1988 emergency admissions to general medical and surgical beds were monitored prospectively in two group practices. The Weybridge practice, with five partners and about 10000 patients, received discharge notes from a hospital that used the combined discharge note and prescription form. The Dover practice, with four partners, one trainee, and about 8000 patients, received discharge notes from a hospital that used separate discharge notes. Both practices received typed final summaries. The notes and the final summaries were 
before any information was received, though the difference was not significant $(p=0 \cdot 2)$.

Weybridge practice

combined discharge

note and prescription for drugs to be taken home) (separate discharge note)

\begin{tabular}{lcc}
\hline No of patients admitted to hospital & 57 & 62 \\
No of deaths in hospital & 7 & 2 \\
No of patients discharged & 50 & 60 \\
No (\%) of discharge notes received & $36(72)$ & $44(73)$ \\
Delay in receiving discharge notes (days after discharge): & & $4 \cdot 5$ \\
$\quad$ Mean & $3 \cdot 0$ & $1-13$ \\
Range & $1-8$ & $3 \cdot 1$ \\
$\quad$ Median & $2 \cdot 1$ & $36(60)$ \\
No(\%) of typed summaries received & $36(72)$ & $29 \cdot 5$ \\
Delay in receiving typed summaries (days after discharge): & $31 \cdot 0$ & $8-75$ \\
Mean & $4-92$ & $18 \cdot 5$ \\
Range & 17 & $14(23)$ \\
Median & & \\
No(\%) of patients seen by general practitioner before any & $7(14)$ & \\
information was received & &
\end{tabular}

posted in both systems and not given to the patient to deliver by hand.

All letters received from the hospitals were stamped with the date and kept. The time taken for both discharge notes and typed summaries to reach the practices was measured in days after the patient's discharge. Three months after discharge we assumed that no further information was going to be received. A record was also kept of whether the patient was seen by one of the general practitioners before any information had been received from the hospital.

The table shows the results. The discharge notes reached the Weybridge practice significantly more quickly than the Dover practice $(p=0.03$, MannWhitney $U$ test), the median delay being 1.0 day shorter with the combined system. No significant difference was seen in the delay for the typed summaries $(p=0 \cdot 8$, Mann-Whitney $U$ test). A higher percentage of patients in the Dover practice were seen

\section{Comment}

Our results suggest that a discharge note that doubles as a prescription for drugs to be taken home will reach the general practitioner more quickly on average. For those patients discharged without a prescription a discharge note may not have been written in this combined system, but in both systems a discharge note was not received for over a quarter of the patients. Penney found that when patients were asked to deliver their discharge notes by hand to their general practitioner the notes took an average of $4 \cdot 3$ days to reach the practice and did not arrive at all in $17 \%$ of cases.

In our study differences between the two hospitals such as throughput of patients, the rate at which the junior medical and clerical staff worked, and postal arrangements were not controlled for, though despite this the time taken for the typed summaries to arrive was similar in the two systems.

Hospitals that use a separate discharge note should consider changing over to the combined discharge note and prescription form. A study could then compare the efficiency of the two types of discharge note within the same hospital, controlling for some of the confounding variables.

1 Lockwood E, McCallum FM. Patients discharged from hospital: an aspect of communication in the health service. Health Bulletin 1970;28:75-80.

2 Tulloch AJ, Fowler GH, McMullan JJ, Spence JM. Hospital discharge reports: content and design. Br Med f 1975; ;iv:443-6.

3 Mageean RJ. Study of "discharge communications" from hospital. Br Med $\mathcal{J}$ 1986;293:1283-4.

4 Pennev TM. Delayed communications between hospitals and general practitioners: where does the problem lie? Br Med f 1988;297:28-9.

Accepted 24 October 1988

\section{Timolol: a non-sedative anxiolytic premedicant for day cases}

\section{John W Mackenzie, Jane Bird}

\section{Department of}

Anaesthetics and Intensive Care, Royal Berkshire

Hospital, Reading,

Berkshire RG1 5AN

John W Mackenzie, FFARCS, registrar

Jane Bird, FFARCS, senior registrar

\section{Correspondence to:}

Dr J W Mackenzie,

Nuffield Department of

Anaesthetics, Radcliffe

Infirmary, Oxford

JX2 $6 \mathrm{HE}$

3r.Med f 1989;298:363-4
Nowadays many patients undergo minor operations on a day case basis. Pharmacological relief of anxiety then presents a dilemma as rapid return of psychomotor function is required. Though short acting sedatives have been advocated, ${ }^{12}$ some patients experience prolonged effects, ${ }^{3}$ and use of such agents is not universal. A non-sedative anxiolytic would eliminate this dilemma. Small doses of $\beta$ blockers are non-sedative and effective in reducing situational anxiety. ${ }^{+}$After receiving ethical approval we studied the effect of oral timolol $(10 \mathrm{mg})$ as a premedicant in a double blind, placebo controlled trial.

\section{Patients, methods, and results}

We studied 100 patients (40 undergoing gynaecological procedures, and 60 undergoing dental extraction who received a standardised anaesthetic to compare return of psychomotor function). Informed consent was obtained, and the patients were told that a placebo might be administered. The quality of the patient's previous anaesthetic experience (none, unpleasant, or pleasant) was noted. Before administration of the tablet baseline blood pressure and pulse rate were recorded and variables of alertness (critical flicker fusion threshold $)^{5}$ and anxiety measured. Anxiety was assessed with a $100 \mathrm{~mm}$ visual analogue scale and the modified multiple affect adjective checklist.'

Anxiety was reassessed immediately before induction of anaesthesia (a mean of 72 minutes after administration of the tablet), and blood pressure and pulse rate were recorded then and during the operation. No arrhythmias were seen in either the timolol or placebo group during the study.

Postoperatively critical flicker fusion thresholds were estimated at $15,30,60$, and 120 minutes after the time of entry to the recovery ward. No significant difference was seen between the groups initially or postoperatively, and psychomotor recovery was judged complete at 120 minutes as critical flicker fusion thresholds were no different from baseline values at this time.

An earlier study (unpublished observation) had

Anxiety scores before and after nervous patients with no previous or unpleasant previous experience with anaesthesia took tablet of placebo or timolol. Figures are means and $95 \%$ confidence intervals

\begin{tabular}{|c|c|c|c|c|c|c|}
\hline & \multicolumn{3}{|c|}{ Visual analogue scale } & \multicolumn{3}{|c|}{ Multiple affect adjective checklist } \\
\hline & Before & After & Change & Before & After & Change \\
\hline $\begin{array}{l}\text { Placebo }(n=25) \\
\text { Timolol }(n=25)\end{array}$ & $\begin{array}{l}51 \cdot 0(42 \cdot 1 \text { to } 59 \cdot 9) \\
44 \cdot 3(35 \cdot 6 \text { to } 52 \cdot 0)\end{array}$ & $\begin{array}{l}50 \cdot 4(38 \cdot 4 \text { to } 62 \cdot 4) \\
35 \cdot 6(29 \cdot 0 \text { to } 42 \cdot 2)\end{array}$ & $\begin{array}{l}0 \cdot 6(-7 \cdot 8 \text { to } 9 \cdot 0) \\
8 \cdot 7(1 \cdot 1 \text { to } 16 \cdot 3)\end{array}$ & $\begin{array}{r}10 \cdot 9(9 \cdot 0 \text { to } 11 \cdot 8) \\
9 \cdot 4(7 \cdot 8 \text { to } 11 \cdot 0)\end{array}$ & $\begin{array}{r}11 \cdot 2(9 \cdot 0 \text { to } 13 \cdot 4) \\
7 \cdot 4(4 \cdot 5 \text { to } 10 \cdot 3)\end{array}$ & $\begin{array}{c}-0 \cdot 3(-2 \cdot 0 \text { to } 1 \cdot 4) \\
2 \cdot 0(1 \cdot 2 \text { to } 2 \cdot 8)\end{array}$ \\
\hline
\end{tabular}

